\title{
Development of Microcontroller Based Electronic Voting Machine(EVM)
}

\author{
Mr. Soumen Ghosh \\ Department of Electronics and Instrumentation Engineering, \\ JIS College of Engineering, Kalyani, Pin 741235, India
}

\begin{abstract}
This paper deals with the design of microcontroller based Electronic Voting Machine. It has the provisions for casting vote among the four candidates by pressing the switches and after completing the voting process total result will be displayed in the LCD. Starting and the ending of the voting process is done by the polling officers.
\end{abstract}

Keywords: Electronic Voting Machine, Microcontroller AT89C51, LCD, Switches.

\section{INTRODUCTION}

India is world's largest democracy. Fundamental right to vote or simply voting in elections forms the basis of Indian democracy. In India all earlier elections be it state elections or centre elections a voter used to cast his/her vote to his/her favorite candidate by putting the stamp against his/her name and then folding the ballot paper as per a prescribed method before putting it in the Ballot box. This is a long, time-consuming process and very much prone to errors. This situation continued till election scene was completely changed by electronic voting machine. No more ballot paper, ballot boxes, stamping, etc. all this condensed into a simple box called ballot unit of the electronic voting machine. EVM is capable of saving considerable printing stationery and transport of large volumes of electoral material. It is easy to transport, store, and maintain. It completely rules out the chance of invalid votes. Use of EVM results in reduction of polling time, resulting in fewer problems in electoral preparations, law and order candidates' expenditure, etc. and easy and accurate counting without any mischief at the counting centre. It is also echo friendly. Our Electronic Voting Machine is microcontroller based having facility of storing of votes of four candidates by pressing switches, options of display in LCD the votes, total result etc.

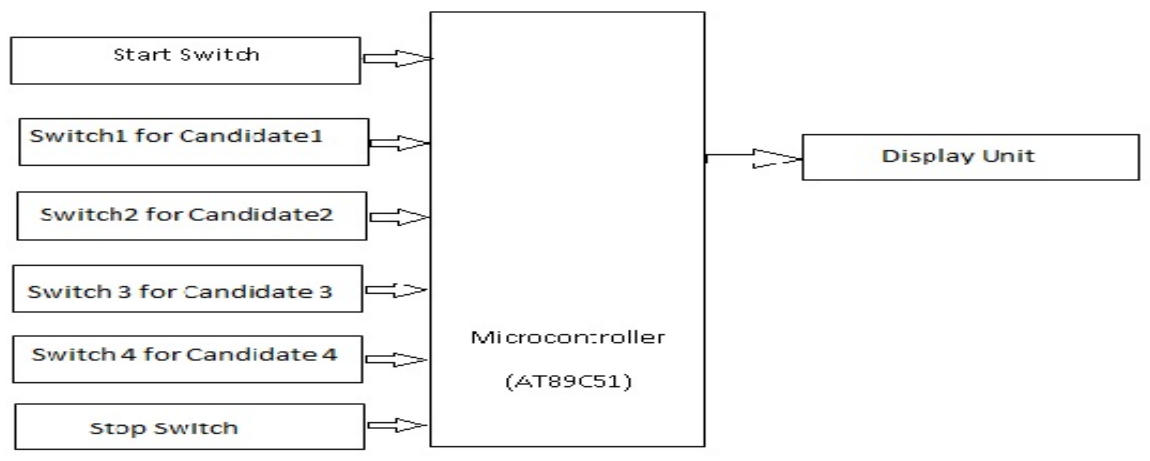

Fig.1. Block diagram of the Electronic Voting Machine

\section{Design Of Electronic Voting Machine}

In this project there are two switches one for starting EVM another for ending the voting process. A set of switches are provided through which a user can cast vote. After every cast of vote, the subsequent count can be seen on the LCD display. The LCD and switches are controlled through AT89C51 microcontroller. In this machine we have the provision of casting votes for the candidates has been provided through four of these switches. These switches are made active high and connected to pins of the controller. These switches are connected in the port 1 of the microcontroller. These switches are made active high. The remaining two switches are to start and stop the voting procedure. These two switches are made active low. The start switch initializes the voting system when pressed, while press the stop switch ends the voting and displays the poll results on LCD screen. These two switches are must not be controlled by the candidate it should be controlled by polling officer. The display device LCD is connected to the port 2 of the microcontroller . 


\section{Components Used And Description}

i). The major components of this system are as follows

ii)AT89C51 microcontroller,

iii) Six tactile switches

iv) $16 * 2 \mathrm{LCD}$

v) 5 volt DC power supply

AT89C51 microcontroller: In this hardware we have used AT89C51 microcontroller. It is 8 bit microcontroller having four ports. Each port is 8 bit. It has $4 \mathrm{~K}$ bytes of flash, 128 bytes of RAM two 16-bit timer/counters. We have written this programme in assembly languages. This programme is compiled and Hex code is generated by software. This hex file is burnt into the microcontroller by universal ROM burner. As this microcontroller has some memory space so we can store large number of data. We can also interface external RAM with this microcontroller for storing more data. With this microcontroller six switches are interfaced to port 1.

Tactile switches: These switches are in this hardware six switches are interfaced, out of these two switches are active low. One switch is for starting the voting machine. When this switch is pressed user is prompted to vote. When the stop button is pressed, the names of the candidates are displayed along with their vote counts. Other four switches are for four candidates. Public select one of these switches and after pressing one switch thank you message will be displayed.

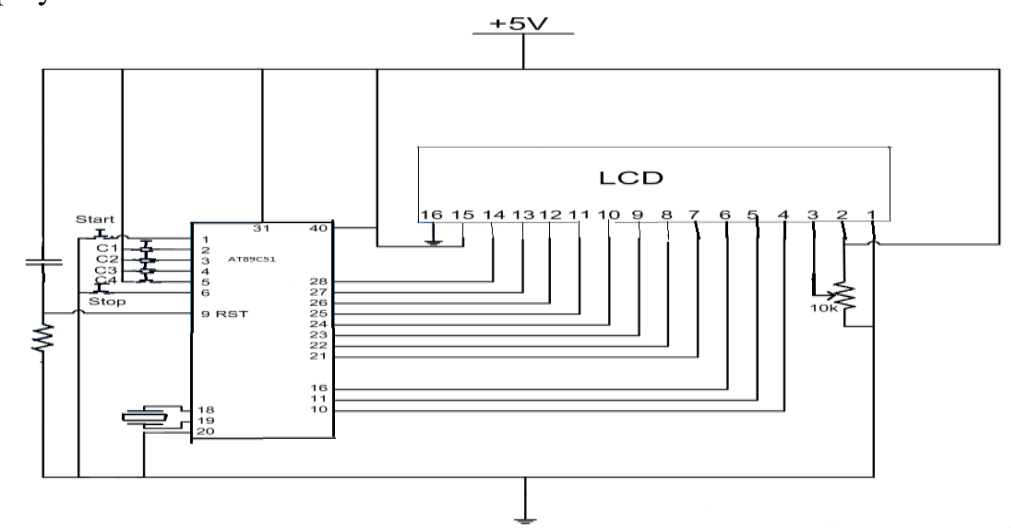

Fig.2. Total circuit diagram

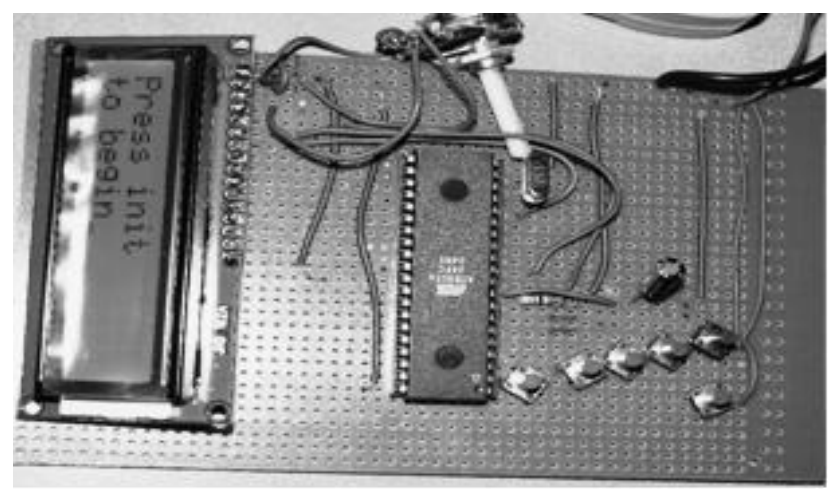

Fig.3. Photographic view of the hardware when power supply is given

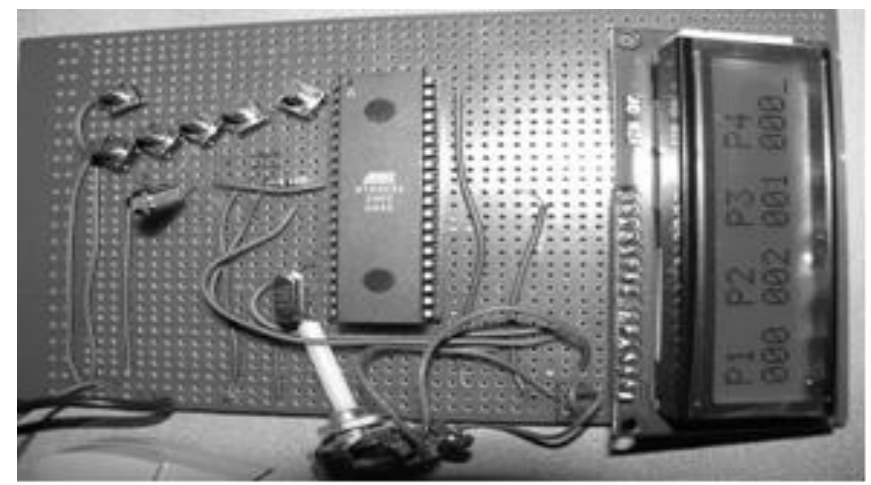

Fig.4. Photographic view of the hardware when vote count is displayed. 


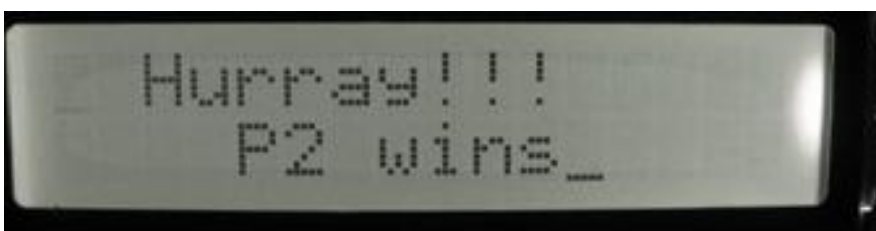

Fig.5. Photographic view of the hardware when result is displayed.

\section{Conclusion}

In this electronic voting machine we have option of choosing one candidate among four candidates. We can also increase the number of candidates. By interfacing 8255 IC we can increase the number of switches for candidates. It could be interfaced with printer to get the hard copy of the result almost instantly from the machine itself. It could also be interfaced with the personal computer and result could be stored in the central server and its backup could be taken on the other backend servers. Again, once the result is on the server it could be relayed on the network to various offices of the election conducting authority. Thus our project could make the result available any corner of the world in a matter of seconds. In days of using nonpolluting and environment friendly resources of energy it could pose a very good example.

\section{REFERENCES}

\section{Books:}

[1] Mazidi Md.Ali, Mazidi J.G., McKinlay R. D., the 8051 microcontroller \& embedded systems, (Pearson Prentice Hall, Delhi, 2006). Proceedings Papers:

[2] umar, D.A.; Dept. of Comput. Sci., Gov. Arts Coll., Trichy, India ; Begum, T.U.S. ,Electronic voting machine - A review ,Pattern Recognition, Informatics and Medical Engineering (PRIME), 2012 International Conference,21-23 March 2012

[3] Alam, M.R. ; Univ. Kebangsaan Malaysia ; Masum, M. ; Rahman, M. ; Rahman, A.,Design and implementation of microprocessor based electronic voting system, Computer and Information Technology, 2008. ICCIT 2008. 11th International Conference, 24-27 Dec. 2008 .

[4] Molnar, D. ; California Univ., Berkeley, CA ; Kohno, T. ; Sastry, N. ; Wagner, D.,Tamper-evident, history-independent, subliminalfree data structures on PROM storage -or- how to store ballots on a voting machine, Security and Privacy, 2006 IEEE Symposium, 21-24 May 2006. 